This is a post-print version of the following article: Vargas-Urpi, Mireia (2018). Sight translation in Public service interpreting: a dyadic or triadic exchange? The Interpreter and Translator Trainer. DOI: 10.1080/1750399X.2018.1503834

\title{
Sight translation in Public Service Interpreting: a dyadic or triadic exchange?
}

\section{Mireia Vargas-Urpi}

Sight translation (ST) has always been considered one of the tasks covered in Public Service Interpreting (PSI). It has been included in handbooks, and it is also a frequent exercise in PSI assessment. However, few studies have analysed how ST is performed in the framework of a triadic interaction. This study is an attempt to redress this gap and is part of a larger experimental research project based on simulations. Five Chinese-Spanish/Catalan interpreters and intercultural mediators were asked to interpret in a series of interactions that recreated meetings between public service providers and Chinese users in social services and education. One simulation included an ST task, which is the focus of this article. It was possible to draw comparisons between the participants in the study because they all had to perform the same ST task under almost identical conditions. The simulations were recorded so they could be transcribed and analysed. Analysis of the data reflects that ST is not monologic, as is often presented in handbooks or assessment exercises, but dialogic, either dyadic or triadic, with meaning being co-constructed orally. The intercultural mediation strategies used by some of the participants in the study are also considered in the discussion.

Keywords: public service interpreting, sight translation, intercultural mediation, reflexive coordination, dialogue interpreting

\section{Introduction}

Research into public service interpreting (PSI) has flourished in recent years. Certain topics have remained at the core of debates since the first contributions to PSI (i.e. the public service interpreter role, ethics and standards of practice, training, or 
accreditation). However, new topics have been emerging ever since the first Critical Link was held in 1995, although surprisingly sight translation (ST) has attracted little attention in these analyses of the interaction and, to date, in the current state of art there is a lack of ST description based on empirical data of triadic encounters.

In contrast, ST has always been considered a part of the functions performed by public service interpreters (see, for instance, Bancroft [2015, 227]; Corsellis [2008, 60]; De Pedro Ricoy [2010, 101] or Hale [2007, 126; 2015, 67]), and has also been included in PSI training materials. Mikkelson $(2014,14)$ even includes ST in the list of "knowledge, skills and abilities public service interpreters should acquire before embarking on their careers."

Given this background, this article attempts to describe ST in triadic interactions in social services from an empirical perspective. Consequently, it works from qualitative research based on simulations of interpreter-mediated interactions. For the most part, the description of the performance by five interpreter/mediators and the ensuing discussion are an attempt to provide information for teaching practices and to challenge the predominant monologic perspective of ST to date.

In Spain and in Catalonia, where this study was conducted, both intercultural mediators and public service interpreters share the responsibility of facilitating communication between public service providers and users with limited official language proficiency. The differences between these two professionals have been thoroughly explained in previous studies (cf. Arumí [forthcoming]; Arumí and VargasUrpi, 2017; García-Beyaert and Serrano Pons, 2009; Vargas-Urpi and Arumí, 2014; Vargas-Urpi 2013), but they can be reduced to two main differences: functions and role in the triadic encounter. 
Concerning their function, public service interpreters are limited to enabling communication in triadic interactions (i.e. providing dialogue interpreting and ST when requested). Intercultural mediators undertake a wider range of tasks: enable communication in triadic encounters, but also advise public service providers about the users' culture; guide users on how to access and benefit from certain public services, especially in healthcare; involve themselves in activities to promote intercultural relations among the various communities that share common spaces in the neighbourhood; and may even act as mediators when there is some kind of dispute arising from cultural differences (Vargas-Urpi, 2013).

Concerning their role in the triadic exchange, interpreters should adhere to the impartial model, i.e., they should interpret accurately, maintaining both the content and the style or register of the message, and they should limit their interventions to specific circumstances: "when they need clarification of part of a message; they cannot hear what is being said; they believe a cultural inference has been missed; they believe there is a misunderstanding" (Cambridge, 2002, 123). The intercultural mediators' role admits a more active intervention (García-Beyaert and Serrano Pons, 2009), and they may use their own voice to talk to each of the participants in the interaction in order to reach a mutual understanding. The intercultural mediator must ensure that all the participants in the exchange can make decisions that respond to their needs, interests and specificities (Prats and Uribe, 2009, 271). For this reason, Sales Salvador $(2014,57)$ suggests talking about multipartiality: the intercultural mediator does not favour any of the participants in the interaction, but rather favours them all (De Luise and Morelli, 2007).

Baraldi and Gavioli $(2014,339)$ explore different reasons why communication is still effective even though intercultural mediators challenge interpreting norms and behaviour. The notion of "reflexive coordination" may account for some of the 
monolingual dyadic sequences that take place in interpreter-mediated interactions and that seek to co-construct meaning and achieve "understanding and promotion of the relevant participants' perspective" (Baraldi and Gavioli, 2014, 349).

\section{Sight translation in previous studies}

This section reviews the research into ST in general and more specifically as part of PSI practice. It is by no means exhaustive, but instead attempts to provide a glimpse of the major trends on this topic, which has always been tightly related to interpreter training, but still has been clearly under researched in comparison to other interpreting modalities (Cenkova, 2015, 375; Li, 2014, 67). ${ }^{1}$

One of the most comprehensive contributions to the study of ST is the dissertation by Jiménez Ivars (1999), which is a descriptive analysis of what has generally been considered an interpreting modality. Among the topics covered, Jiménez Ivars $(1999,142)$ discusses the debate over the various denominations ST has received, acknowledging that several authors have advocated the use of 'sight interpreting', which would better reflect the simultaneous mode of the practice (see also Pöchhacker [2004, 19]). Jiménez Ivars $(1999,151)$ then classifies previous research according to the following categories: (a) studies focusing on the process; (b) studies focusing on the result; (c) studies focusing on didactics; and (d) studies focusing on professional issues. What is also interesting in Jiménez Ivars' dissertation is the distinction between the communicative function, when ST entails a live oral translation for a real listener, and the instrumental function, when it is used as a means to an end either in the process

\footnotetext{
${ }^{1}$ For a detailed and updated revision of previous research in sight translation, see Li (2014) and Chen (2015).
} 
of translating a written text, or in the achievement of a training goal (Jiménez Ivars and Hurtado Albir, 2003). As Pöchhacker $(2004,186)$ points out, the instrumental function, i.e. the use of ST as a preliminary exercise or an aptitude test in interpreting education, has received more scholarly attention than ST as a curricular component on its own.

According to Chen (2015: 146), incorporating ST in interpreting courses has "benefits in terms of developing quick reactions, thorough comprehension, and flexible oral skills among trainee interpreters."

Even though Jiménez Ivars briefly mentions ST in court interpreting settings, there is a clear focus on conference interpreting throughout her dissertation. This also seems to be the case in most studies about ST, either descriptive or empirical, and this reflects the importance that ST has had in conference interpreting, both in practice (especially in the so-called "simultaneous interpreting with text") and in education.

Among the studies about ST in conference interpreting practice or training, Weber (1990) provides a detailed description of the process for ST when it is used to complement consecutive or simultaneous interpreting; Viezzi (1989) studies how effective ST may be in the acquisition of the required skills for simultaneous interpreting, a question that Iglesias Fernández (2003) also asks in a survey carried out with conference interpreting trainers; and Agrifoglio (2004) compares the performance of six professional interpreters in ST, simultaneous interpreting and consecutive interpreting with a view to identifying particular constraints and problems. These examples show the predominance of the monologic perspective in the study of ST.

Concerning PSI, ST has always been considered a task public service interpreters should take on. Bancroft $(2015,227)$ clearly states that it is "widely needed in community interpreting to convey to service users the meaning of forms, prescriptions, legal documents and many other texts provided as part of the service." 
Similarly, Cenkova $(2015,375)$, mentions the following examples of ST tasks in community-based institutional settings: "in back-translating the written record of an interpreter-mediated interview in police settings and asylum settings, for rendering expert witness statements in courtroom interpreting or for medical reports and patient files in healthcare interpreting."

However, few empirical studies have included examples of how interpreters actually deal with ST tasks in public services. One of the exceptions to this is Wadensjö's $(1998,217)$ example of a real interaction that involved an ST of a report typed by a police officer. Her example shows how this task is interrupted by the user, an applicant for a prolongation of a temporary residence permit in Sweden, who tries to confirm the information rendered by the interpreter and initiates a monolingual exchange with the interpreter. The interpreter finally involves the police officer, thus producing a bilingual triadic exchange. These kinds of examples are rare, because most studies concerning the analysis of real interactions in PSI have not analysed ST tasks.

ST has also been included in PSI or dialogue interpreting training materials. When approaching the practice of ST, some handbooks suggest monologic exercises where trainees are asked to reproduce the content of a written text orally, either as an autonomous activity at home (Valero-Garcés, 2008, 185), or as a preliminary exercise or "ice-breaker" in the classroom, as in Rudvin and Tomassini $(2011,98)$. According to them, " $[\mathrm{t}]$ hose students who have not previously had any interpreter training at all might benefit from preliminary exercises such as short sight translations and memory tests to train their reactive competence and to gently ease them into the more challenging interpreting tasks.”

Bancroft and Rubio-Fitzpatrick (2011, 118-119) take a closer look at this task when providing detailed advice on how it should be performed. Some of their 
recommendations include not sight translating texts that are too long or too complex instead, the interpreter may ask the provider to explain or summarise the content of the document — or making sure the provider stays in the room while the text is sight translated. The latter is also included as a guideline by the National Council on Interpreting in Health Care (NCIHC, 2009, 7) in the following terms: "Documents with specific instructions are appropriate for sight translation, with the provider present, so that the patient's questions can be answered by the provider, not the interpreter."2 This is certainly a revealing guideline because it recognises the importance of maintaining the triadic interaction during the performance of the task and implicitly challenges the monologic perspective of ST.

Bancroft and Rubio-Fitzpatrick discourage interpreters from simplifying the register of the document, even when the syntax or the vocabulary are too complex for the users, and also warn them against summarising the content of the document. The NCIHC's stance regarding complex documents is slightly different, as they specifically advice not to sight translate certain texts, as inferred in the following guideline:

Legal documents, such as consent forms, should be translated professionally and then, if necessary, read aloud by the interpreter for the benefit of the client. [...] [L]egal documents are usually written in complex and formal language, with many legal terms. Medical interpreters are often unfamiliar with this high register legal terminology and are at risk for rendering it inaccurately if required to translate it on site. [...] [E]ven with a translated consent form, a provider needs to be present while the patient reads the form (or the interpreter reads it to the patient), so as to answer questions and guide the interpreter if there is text that can be omitted. (NCIHC, 2009, 7).

Finally, ST has also had a relevant position in assessment tasks: in selection processes

\footnotetext{
${ }^{2}$ Emphasis in the original.
} 
or admission exams for PSI courses, in assessment at the end of training, and in accreditation exams such as the Diploma in Public Service Interpreting (DPSI) in the UK, or the professional interpreter testing of the National Accreditation Authority for Translators and Interpreters (NAATI) (2015) in Australia. Corsellis $(2008,60)$ argues that it is an exercise that reflects "the ability to transfer meaning accurately between languages, both ways" — one of the skills required by a public service interpreter according to the National Occupational Standards for Interpreters in the UK. Among the guidelines regarding this exercise according to the DPSI Handbook (IOL Educational Trust, 2015, 8), candidates are not allowed to use dictionaries or glossaries, to take notes during the preparation time nor to annotate or mark the text in any way. As for the assessment criteria for the ST exercise, the DPSI Handbook mentions completeness (all the information is transferred accurately and without omissions, additions or distortions); accuracy and appropriateness (the language used is appropriate and clear); and fluency and pronunciation (IOL Educational Trust, 2015, 14).

\section{Method}

This study on ST is part of a larger project developed by the MIRAS research group. ${ }^{3}$ Its objective was to study the strategic behaviour of public service interpreters in social services and education, focusing on the example of the Chinese-Spanish/Catalan language combination (Arumí and Vargas-Urpi, 2017). This exploratory study combined qualitative research methodology with a multidisciplinary approach. The primary method of data collection was the recording of simulations of interpreted situations in social services and education settings. These data were complemented by

\footnotetext{
${ }^{3}$ For more information about the group, see: http://grupsderecerca.uab.cat/miras/
} 
the information retrieved by means of an initial questionnaire which collected basic information about the participants, and retrospective interviews conducted after the simulations with the interpreters and mediators taking part in the study. This section will only refer to the description of the method used to study the exercise of ST, even though the method for the general project was a bit more complex. ${ }^{4}$

\subsection{Design of the simulation and of the other data collection tools}

Three scripts covering three different situations were designed for the general project. They were all inspired by cases observed in the previous research conducted by members of the group or in their respective professional experience. The ST task was part of the second simulation, which recreated a meeting in a student enrolment and placement office, i.e., the place where parents must go when they have just arrived in a new city and are looking for a school for their children. In this simulation, one of the group's researchers played the role of the service provider, a social educator working at the office; and a collaborator, native Chinese, acted as the user, a Chinese mother applying for a school to register her son who had just arrived from China half-way through the school year. Even though both Spanish and Catalan are spoken at public services in Catalonia, in this simulation the provider spoke Spanish and the user spoke Standard Chinese.

The ST task was included almost at the end of the meeting. The provider directly addressed the interpreter and asked her the following: "Please, tell her that I need her to bring some documents. Look through and translate this paper which lists the documents

\footnotetext{
${ }^{4}$ For more information about the methodology used for the general project, see Arumí and Vargas-Urpi (2017).
} 
she will have to bring as soon as possible." Afterwards, the provider would give the paper with the list of documents to the interpreter and she would start the task. The original text for the ST, included in annex 1 along with an English translation, was copied from an institutional website containing information about the requirements for registering children in a Catalan school.

The text is short (126 words) but challenging, as it includes specific terminology concerning administrative procedures and documents, as well as certain elements that may be considered cultural references. An example for this is the libro de familia, literally, the "family book", which is a little blue book that couples are given in Spain when they register the birth of their first child. The book lists the members of the family, and if other children are born afterwards, they are also included in the book. The book is only given if the children are born in Spain, which is why most foreign parents have never heard about this book if their children were born outside Spain. Another difficult term is the volante municipal de convivencia, which is a document listing the people registered as living in a same house or flat, issued at a citizen services office. Besides being closely linked to a specific procedure in Spain (known as empadronarse, or registering at the population register of a town), this term is also difficult because it is not the most common term used for this purpose. Finally, another difficulty is the structure of the text, which is a bit confusing and unclear, because the information of the last sentence refers to clauses 1.1 and 1.2, not to clause 2. Furthermore, this sentence was especially important in the simulated parent-teacher meeting because it applies to foreign children.

In parallel, we also designed a questionnaire to be completed before the interview and a script for a retrospective interview which was conducted after the simulations. The initial questionnaire included simple questions designed to gather basic 
information on the work experience of the interpreters who were taking part in the study (years of experience, areas of work, specific training, etc.). For the retrospective interviews, a semi-structured interview script was prepared, enabling the interviewer to adapt the questions to obtain the most relevant information from the participating interpreters. As part of the interview, the interpreters were specifically asked about the ST task.

\subsection{Data collection (recording of simulations)}

For the data collection, five participants were selected, all women, who offered the Chinese-Spanish/Catalan combination and had experience in PSI. Before starting the simulations, all the participants signed an informed consent form, confirming they had received all the information on the study and gave their explicit consent to be recorded. They were then asked to interpret or behave as they would in their daily work. A static camera was focused directly on the participant who was called to interpret but it also showed the various participants in profile. This way the physical presence of recording technicians, which could have been a distraction, was avoided during the simulations. The retrospective interview was also recorded.

\subsection{Data analysis}

All the simulations were transcribed and analysed by means of textual analysis, comparing the renditions with the original text for the ST, but also relating them to the previous and following turns and to the overall interaction. A detailed account of the data analysis is provided under section 5.

\subsection{The sample of participants}

Of the five participants, two were born in Catalonia, one in France (of Spanish parents) 
and two in China. Their mother tongues were therefore recorded as Catalan, Spanish and Chinese, respectively. Four of them introduced themselves as intercultural mediators, and the other one as an interpreter. None of them had received specific training in PSI, even though two of them (participants 1 and 5) had a BA in Translation and Interpreting. ${ }^{5}$ Three had attended short courses or workshops in intercultural mediation (participants 1,2 and 5).

Although our intention was to include only interpreters who had at least three years' experience in social services and education, the contractual status and job instability of public service interpreters in Spain meant that we were unable to find interpreters who met this condition. Therefore, the final study also included intercultural mediators, who usually take on dialogue interpreting tasks in Catalonia. Despite being untrained professionals in the field of PSI, the participants had broad experience in enabling communication between Chinese users and local service providers, which is why they were accepted as participants in the study. Furthermore, we considered that the study of intercultural mediators' strategies when acting as dialogue interpreters was also important to understand the reality of communicative practices in Catalonia and Spain.

Table 6 in the annex 2 summarises the information about participants' background and experience.

\subsection{Limitations}

Being an exploratory study, two major limitations must be acknowledged. First, the

\footnotetext{
${ }^{5}$ Subjects concerning PSI have been introduced relatively recently in Spanish Degrees in Translation and Interpreting (Vargas-Urpi, 2016).
} 
artificiality of the simulated interactions must be discussed. The use of simulations has clear advantages, and it was especially chosen for this research because we wanted to compare interpreters and mediators' performance and strategies in reaction to the same interactional problems. However, the experimental approach impinges on participants' spontaneity and this must be taken into account when analysing the data.

Second, the sample of participants in the study is relatively small, meaning that results are not generalisable. Nevertheless, this should not be a problem in qualitative research whose objective is to produce a detailed description of each participant's behaviour, as a first attempt to shed light onto ST as a relatively unexplored task in PSI practice.

\section{Data analysis: Sight translation as a dialogue}

When asked to perform the ST task, all the participants in this research share some common reactions and strategies. First, they all accept the task with a slight nod, two of them also uttering "okay" (vale). ${ }^{6}$ They all immediately take the paper and start sight translating without any kind of previous preparation. None of them reads the whole text first as suggested by Bancroft and Rubio-Fitzpatrick $(2011,118)$, among others. None of them asks anything to the provider before starting the task.

Certain strategic uses of non-verbal language are also common among the interpreters. They all take the paper and use one of their fingers or a capped pen to trace out what they are sight translating, showing at all times the paper to the user. This may be regarded as a transparency strategy, so as to show what part of the content is being

\footnotetext{
${ }^{6}$ Participants' utterances have been translated from Spanish and Chinese into English for the purpose of this article.
} 
translated. Another non-verbal cue all the participants share is the strategic use of gaze to seek for comprehension tokens by the user, the recipient of the ST. Generally, participants sight translate a piece of information, pause, gaze at the user, and wait for any kind of token of comprehension, which usually is a nod or a discourse marker such as “okay" or “fine” (好, hao; 行, xing) uttered by the user.

ST is not a monologic task in any of the experiments, and this is not only because the user asks questions while she is receiving the translated information, but also because the participants actively engage the user while trying to ensure her comprehension and seek to co-construct the message and negotiate meanings with her; some examples are provided in the extracts below. There are certain differences, though, in this dialogic approach to the task.

The main difference is whether the provider is involved to a certain degree in this dialogue, or is completely excluded from it. Participant 4 is the one who engages the provider more systematically, providing a rendition of most of the questions the user asks. Extract 1 shows how this triadic interaction develops when the interpretermediator tries to explain the meaning of the family book (libro de familia) to the user:

\section{Extract 1.}

[Table 1 to be included here]

As may be noted in this extract, participant 4 first tries to explain the meaning of the document herself and engages in a brief monolingual exchange with the user (turns 34), but soon involves the provider in the conversation when providing a sort of summarised rendition in turn 6. The zero and non-renditions (Wadensjö, 1998) observed in turns 2-5 have the objective of clarifying the meaning of "family book" and making it relevant for the user, which could be considered a form of reflexive coordination, using 
Baraldi and Gavioli's term (2012).

The different solutions the participants choose for the problem of the cultural element "family book" are indeed interesting to analyse, because all the interpreters have to deal with this problem at the very beginning of the ST task and, since this is certainly a difficult term to render in Chinese, any kind of translation generates questions by the user. Extract 2 shows how participant 1 handles this reference.

Extract 2.

[Table 2 to be included here]

In extract 2 we see how the interpreter-mediator, aware of the fact that the user may not have the family book if the child was born in China, directly asks her this question. This could also be regarded as a strategy to look for the most relevant information for the user, and reflects a certain degree of thematic knowledge - this question was clearly influenced by the interpreter-mediator's experience in the field of social services. The interpreter-mediator then suggests that the mother bring the birth certificate instead, which is the document to certify filiation usually requested of foreign families that do not have a family book. Even though a specific alternative to the family book is already explained at the end of the text (the child's passport would be enough), it is not mentioned by the interpreter. Concerning the rest of the task, participant 1 does not involve the provider at all. She answers all the user's questions herself, as in the previous extract, and directly omits the information that she assumes that does not apply to the user.

Participant 2's behaviour is similar. She also assumes that the user "must not have the family book, because the child was born in China," and then she concludes that the user does not need to bring that. She does not suggest any alternative and omits the 
last sentence of the text, which explicitly applies to persons without the family book. However, interpreter 2 does engage the provider on two occasions: first, to check the accuracy of 1.2 regarding ID documents (“mother's, father's, legal guardian's... but not the child's?"). Extract 3 shows the second time participant 2 engages the provider in the interaction.

Extract 3.

[Table 3 to be included here.]

In turn 14 , the interpreter-mediator first attempts to answer herself, but quickly changes her mind and addresses the provider. However, she does not ask the provider to answer the user's question, but instead asks her for permission to provide the answer herself, as she already knows that information, probably due to her previous experience.

As for participant 3 , she changes the order of the information when she starts the ST (see extract 4).

Extract 4.

[Table 4 to be included here.]

Participant 3 does not remember the specific translation for the family book, according to what she also says during the retrospective interview, which is the reason why she prefers not to give a definite translation. During the rest of the task, she also answers most of the users' questions directly and tries to select the most relevant information for the user. For instance, when translating 1.2, she specifies that the document requested is the mother's, and does not make any reference to the father or the legal guardian. She only engages the provider when the user asks where she should go to get the specific 
document mentioned in 2 (as in turn 13 of extract 3), but the participant 3 does render the question to the provider: "As for the cohabitation certificate of residence, she's asking me where she can obtain it."

The behaviour of participants 1,2 and 3 is similar, because they all engage in a dialogue with the user, while the provider is generally left aside, with very few exceptions in the cases of interpreters 2 and 3. Participant 5 starts sight translating the list of documents but when she finds out that the user does not know what a family book is, she asks the provider to keep the list of documents herself (interpreter 5) and explain them to the user when the meeting ends. The provider agrees on that and, after the meeting, when the provider leaves, the interpreter-mediator resumes the task. ${ }^{7}$ During the retrospective interview, she explains that she did so to ensure that the user would completely understand everything, avoiding the time pressure she felt when the provider was there. According to her, providers are always in a rush and are impatient, so she is used to summarising information at the end of the meetings or resuming it when the provider leaves.

During that dyadic exchange, interpreter 5 explains what each of the documents refers to and makes sure that the user understands her. For instance, in the case of the family book she explains: “(...) The first is the family book. This is a notarial certificate, if your child was born in China you might not have it, but you must have some kind of certificate that states the relationship you and your husband have with your child." When the user confirms having understood what this is, the interpreter writes the name of the document in Chinese next to the original. As for the document requested in 2, the interpreter suggests the following:

\footnotetext{
${ }^{7}$ This conversation after the meeting was also recorded.
} 


\section{Extract 5.}

INT5: 然后 ::: 下面写的就说 ::: (...) 你明天早上可以去政府申请一个 volante municipal de convivencia, 您不会说的话没问题, 在这张写得很清楚, 然后跟 他们说一下麻烦 por favor: volante municipal de convivencia, 跟他们说一下, 因 为这个证明啊上面写的您跟您的丈夫跟您的小儿子住在一起, 有谁的家人证 明, 别忘 $[\ldots]$

Then::: written here below, that is to say::: (...) tomorrow morning you should go to the city council and ask for a volante municipal de convivencia, if you cannot say it don't worry, because you have it written here very clear, then you ask them, please por favor: volante municipal de convivencia [pointing at the specific words in the document], you tell them, because this certificate says that you, your husband and your son live together, it's a certificate of who live together, don't forget [...]

The interpreter-mediator gives a lot of information which is not explicit in the written text, but that is certainly necessary for the user to understand what that document is and where she has to go to obtain it. The interpreter-mediator decides to include the words in Spanish to make it clear that the user will need to refer to that specific name and, while pronouncing those words, she also points emphatically at the respective segment in the text.

When the ST task concludes, the participant 5 summarises the information for the user ("look, you will need four documents: the first is the...") and writes down the names in Chinese of the four documents she will need. Participant 1 also summarises the information at the end, whereas participant 2 tries to ensure that the user has understood everything (“is everything clear?”).

\section{Discussion and conclusions}

The previous description and analysis of the simulated interactions show how ST is not a monologic task in certain PSI settings. It may be so in court and police interpreting, where the users' voice is limited by the idiosyncrasy of the institution, but in social 
services, and probably in education and healthcare, we are to expect that users will ask questions to ensure they understand the information. ST is thus dialogic, but a new question arises: does it create a dyadic or a triadic exchange?

We could place the participants of the previous sample in a spectrum: at one end, participant 4 would be closer to the impartial model of PSI and to the direct communication suggested by recently published codes of ethics (García-Beyaert et al., 2015: 9); she renders most of the user's questions to the provider, and this kind of behaviour seems to promote a triadic exchange. At the other end would be participant 5, who reflects strategies more related to intercultural mediation, talking to the user privately and assessing her on how to effectively use the information received; this would be a clear example of ST as a dyadic exchange. Participants 1,2 and 3, would fall in the middle but closer to the intercultural mediation end, because the provider is present during the ST task, but rarely engaged in the conversation. In terms of participation framework and footing (Goffman, 1981), participants 1, 2 and 3 align with the user, and the provider becomes an unaddressed participant according to Goffman (1981) or perhaps even a bystander or unratified participant, because not knowing the language of the exchange during the ST, she is not able to take part in it. This is not the case for participant 1 , who continuously shifts her alignment between the user and the provider, converting them into addressed ratified participants.

The previous examples also show how the interpreter-mediator becomes the participant in control of the situation when the ST begins. In most of the situations they decide what to sight translate and, to do so, they look for the most relevant information considering the user's expectations and needs, which could be regarded as a form of reflexive coordination. Participant 5 also seems to take into account the user's sociocultural background, especially when adopting a pedagogical approach to the way 
of conveying the information (repeating, noting down important things, reviewing the information at the end). Participant 5 tries to empower the user and promote her autonomy in the use of public services, which is one of the objectives of intercultural mediation as a discipline on its own. Participants 1 and 2 are also concerned about the user understanding correctly all the information.

There are certain drawbacks, though, to such an active involvement of the interpreter-mediator. The most obvious danger is that the figure of the provider disappears, because the interpreter-mediator takes on this role. Were there a mistake in the rendering of the information or when providing new information not explicit in the text, this would be the interpreter-mediator's responsibility. Furthermore, this enhanced relationship between the interpreter-mediator and the user substitutes what should be the prevalent relationship in these interactions, i.e. the user-provider relationship, and this may impinge on important issues such as user-provider trust. Last but not least, it directly conflicts with the communicative autonomy of the parties that PSI seeks to support (García-Beyaert, 2016).

The analysis of the performance of participants with wide experience in mediated communication in public services, despite being untrained PSI professionals, may provide new insight into PSI training as well. Furthermore, PSI can learn from intercultural mediation practices, as already noted in previous research (CRIT, 2014).

First, if ST is such a frequent task in PSI as stated in previous research (see section 2) but it often involves a dialogue, the way it is taught should be changed. When using ST not as a pedagogical exercise to prepare for other interpreting modalities (the instrumental function in Jiménez Ivars and Hurtado Albir's [2003] distinction), but as a communicative tool and a task on its own, specific instructions about the task should be given, and examples such as the ones provided in this article should be discussed with 
students. Certain questions would be useful to promote debate among trainees. For instance, in terms of reflexive coordination and seeking to promote effective communication while also considering each participant's interests (e.g. the user needs clear information, but the provider may want to save time), to what extent are monolingual conversations acceptable? What should be the limit? Do they always require a detailed summarised rendition afterwards? The example of the family book reflects that sometimes monolingual conversations are simply an attempt to reach an agreement on the meaning of a specific term between the interpreter and the user (see, for instance, extract 1). In this specific case, and considering the time constraints of most interactions in public services, how detailed should the summarised renditions that update the provider about the monolingual exchange be?

Concerning the practice of ST in the classroom, it should be included as a specific task in a role play situation with a clear context, and not suggested as an isolated monologic exercise. Students taking the roles of the user should be encouraged to ask questions during the ST in order to reflect the dialogic exchange ST turns out to be in PSI.

While the intercultural mediation approach (i.e. ST as a dyadic exchange where the interpreter-mediator provides non-explicit and even non-implicit information) has the clear advantage of saving time, this role is only feasible if the interpreter-mediator possesses extensive thematic competence and detailed knowledge about the field (which was indeed the case of participants 1,2, 3 and 5 in our sample), and if he or she explicitly acts as an intercultural mediator — assuming the task of assessing the user. PSI trainees should be discouraged from undertaking this role for various reasons. First, this role clearly contradicts the impartial model and even goes beyond the idea of reflexive coordination, because interpreter-mediator's zero renditions provide more 
information than that implicit in the text. Second, PSI trainees are often educated to work in various contexts, which is the reason why they cannot master in the thematic knowledge required to assess users and provide such specific information.

However, there are certain strategies that PSI trainees can learn from intercultural mediation. One of these is the strategic use of gaze to engage the user in the interaction and seek for tokens of comprehension. Marking out the text with a finger is also a useful strategy to show transparency. The text selected for the ST of the study contained information that obviously did not apply to the user (e.g. the references to the family book, to the national ID document, or to the student's father or legal guardian, since it was clearly the mother who was applying for the school). Therefore, reflexive coordination could take the shape of making the informant which did apply to the user relevant. Reviewing the most important details at the end of the task is also an empowering strategy, especially when ST implies some kind of action in response, such as bringing documents.

This article is one of the first studies that analyses ST in triadic interactions and covers the four dimensions Jiménez Ivars (1999) detected: it focuses on the process, on the result, on didactics and on professional issues. However, it is exploratory and has a clearly prospective purpose. More research into ST is needed in order to confirm or reject previous assumptions and in order to provide more examples of ST in triadic encounters in other settings and language combinations. Studies including professional public service interpreters are also needed.

\section{Acknowledgements}

This article is part of the project funded by the Spanish Ministry of Economy and Competitiveness: "The quality in translation as an element to safeguard procedural guarantees in criminal proceedings: development of resources to help court interpreters 
of Spanish - Romanian, Arabic, Chinese, French and English" (FFI2014-55029-R). It has also been supported by the AGAUR's recognition of MIRAS research group (2014SGR545).

\section{References}

Agrifoglio, Marjorie. 2004. "Sight translation and interpreting: A comparative analysis of constraints and failures.” Interpreting 6 (1): 43-67. Doi: 10.1075/intp.6.1.05agr

Arumí, Marta. Forthcoming. "The fuzzy boundary between the roles of interpreter and mediator in the Public Services in Catalonia: Analysis of interviews and interpretermediated interactions in the health and education context."

Arumí, Marta, and Mireia Vargas-Urpi. 2017. "Strategies in public service interpreting. A roleplay study of Chinese-Spanish/Catalan interactions.” Interpreting 19 (1): 118-141. Doi: 10.1075/intp.19.1.06aru

Bancroft, Marjory. 2015. "Community interpreting: A profession rooted in social justice." In The Routledge Handbook of Interpreting, edited by Renée Jourdenais and Holly Mikkelson, 217-235. Abingdon: Routledge.

Bancroft, Marjory, and Lourdes Rubio-Fitzpatrick. 2011. The Community Interpreter. A Comprehensive Training Manual. Columbia: Culture and Language Press.

Baraldi, Claudio, and Laura Gavioli. 2012. "Understanding Coordination in InterpreterMediated Interaction.”. In Coordinating Participation in Dialogue Interpreting, edited by Claudio Baraldi and Laura Gavioli, 1-21. Amsterdam: John Benjamins. 
Baraldi, Claudio, and Laura Gavioli. 2014. "Are close renditions the golden standard? Some thoughts on translating accurately in healthcare interpreter-mediated interactions." The Interpreter and Translator Trainer, 8 (3): 336-353. Doi: 10.1080/1750399X.2014.972029

Cambridge, Jan. 2002. "Interlocutor roles and the pressures on interpreters." In Traducción e Interpretación en los Servicios Públicos. Nuevas necesidades para nuevas realidades, edited by Carmen Valero Garcés and Guzmán Mancho Barés, 119-124. Madrid: Universidad de Alcalá.

Cenkova, Ivana. 2015. “Sight Interpreting/Translation.” In The Routledge Encyclopedia of Interpreting Studies, edited by Franz Pöchhacker, 374-375. Abingdon: Routledge.

Chen, Wallace. 2015. "Sight translation”. In The Routledge Handbook of Interpreting, edited by Reneé Jourdenais and Holly Mikkelson, 144-153. Abingdon: Routledge.

Corsellis, Ann. 2008. Public Service Interpreting: The First Steps. Hampshire and New York: Palgrave Macmillan.

CRIT group (ed.). La práctica de la mediación interlingüística e intercultural en el ámbito sanitario. Granada: Comares.

De Luise, Danilo, and Mara Morelli, M. 2007. "Puentes de palabras." In Actas X Simposio Internacional Comunicación Social, 137-141. Santiago de Cuba: Centro de Lingüística Aplicada. 
De Pedro Ricoy, Raquel. 2010. "Training Public Service Interpreters in the UK: A fine balancing act." JoSTrans: The Journal of Specialised Translation, 14: 100-120. [Retrieved from: http://www.jostrans.org/issue14/art_depedro.pdf]

Fernández Iglesias, Emilia. 2003. “La Interpretación en la Universidad española: estudio empírico de la situación académica y didáctica." PhD diss., Universidad de Granada. [Retrieved from: http://hdl.handle.net/10481/28983]

García-Beyaert, Sofía. 2016. “Cross-Linguistic Communication and Public Policy: The Institutionalization of Community Interpreting.” PhD diss., Universitat Autònoma de Barcelona.

García-Beyaert, Sofía; Bancroft, Marjory A.; Allen, Katharine; Carriero-Contreras, Giovanna; and Socarrás-Estrada, Denis. 2015. "Ethics and Standards for the Community Interpreter. An International Training Tool.” In The Community Interpreter: An International Textbook. Columbia: Culture \& Language Press.

García-Beyaert, Sofía, and Jordi Serrano Pons, J. 2009. "Recursos para superar las barreras lingüístico-culturales en los servicios de salud.” In Manual de atención al inmigrante, edited by Joaquín Morera Montes; Alberto Alonso Babarro and Helena Huerga Aramburu, 53-66. Madrid and Barcelona: Ergon. [Retrieved from: http://www.l-in-k.org/Garcia-Beyaert-2009-Recursos-para-superar-barreras-lingcult-en-salud.pdf]

Goffman, Erving. 1981. Forms of talk. University of Pennsylvania.

Hale, Sandra. 2007. Community Interpreting. Hampshire and New York: Palgrave Macmillan. 
Hale, Sandra. 2015. "Community Interpreting." In The Routledge Encyclopedia of Interpreting Studies, edited by Franz Pöchhacker, 65-69. Abingdon: Routledge.

IOL Education Trust. 2015. Diploma in Public Service Interpreting. Handbook for Candidates.

[Retrieved

from: https://www.ciol.org.uk/images/Qualifications/DPSI/DPSI\%20Handbook\%20Oct -15.pdf]

Jiménez Ivars, Amparo. 1999. “La traducción a la vista. Un análisis descriptivo.” PhD diss., Universitat Jaume I. [Retrieved from: http://repositori.uji.es/xmlui/handle/10234/29703]

Jiménez Ivars, Amparo, and Amparo Hurtado Albir. 2003. "Variedades de traducción a la vista. Definición y clasificación.” Trans 7: 47-57. [Retrieved from: http://www.trans.uma.es/pdf/Trans_7/t7_47-57_AJimenez.pdf]

Li, Xiangdong. 2014. "Sight translation as a topic in interpreting research: Progress, problems and prospects." In Across Languages and Cultures 15(1): 67-89. Doi: 10.1556/Acr.15.2014.1.4

Mikkelson, Holly. 2014. "Evolution of Public Service Interpreter Training in the U.S." FITISPos International Journal, 1 (1): 9-22. [Retrieved from: http://www3.uah.es/fitispos_ij/OJS/ojs-2.4.5/index.php/fitispos/article/view/6]

National Accreditation Authority for Translation and Interpreting (NAATI). 2015. Accreditation by Testing. Information Booklet. [Retrieved by: https://www.naati.com.au/PDF/Booklets/Accreditation_by_Testing_booklet.pdf] 
National Council on Interpreting in Health Care. 2009. Sight Translation and Written Translation. Guidelines for Healthcare Interpreters. [Retrieved from: http://www.ncihc.org/assets/documents/publications/Translation_Guidelines_for_ Interpreters_FINAL042709.pdf]

Pöchhacker, Franz. 2004. Introducing Interpreting Studies. London and New York: Routledge.

Prats Sanromán, Genisa, and Elisabeth Uribe Pinillos. 2009. "La mediación intercultural.” In Mediación intercultural en el ámbito de la salud, edited by Miquel Casas, Francisco Collazos and Adil Qureshi, 260-274. Barcelona: La Caixa.

Sales Salvador, Dora. 2014. "La delgada línea roja de la imparcialidad." In La práctica de la mediación interlingüística e intercultural en el ámbito sanitario, edited by CRIT, 55-90. Granada: Comares.

Valero Garcés, Carmen. 2008. Formas de mediación intercultural e interpretación en los servicios públicos. Conceptos, datos y práctica. Granada: Comares.

Vargas-Urpi, Mireia. 2013. "ISP y / o mediación intercultural: la realidad de los profesionales que trabajan en el contexto catalán.” Cuadernos de Aldeeu 25: 131163. [Retrieved from: http://aldeeu.org/cuadernos/index.php/CALDEEEU/article/view/38/30]

Vargas-Urpi, Mireia. 2016. "La difícil tarea de dar respuesta a las necesidades de formación en Interpretación en los Servicios Públicos (ISP) en Cataluña: 10 años de avances y retrocesos.” FITSPos International Journal 3: 92-103. [Retrieved 
from:

http://www3.uah.es/fitispos_ij/OJS/ojs-

\subsection{5/index.php/fitispos/article/view/99]}

Vargas-Urpi, Mireia, and Marta Arumí. 2014. "Estrategias de interpretación en los servicios públicos en el ámbito educativo: estudio de caso en la combinación chino-

catalán.” $\quad$ Intralinea, $16 . \quad$ [Retrieved from: http://www.intralinea.org/archive/article/2040]

Viezzi, Maurizio. 1990. "Sight translation, simultaneous interpretation and information retention." In Aspects of Applied and Experimental Research on Conference Interpretation, edited by: Laura Gran and Christopher Taylor, 54-60. Udine: Campanatto Editore.

Wadensjö, Cecilia. 1998. Interpreting as Interaction. New York: Longman.

Weber, Wilhem. 1990. "The Importance of Sight Translation in an Interpreter Training Program." In Interpreting: Yesterday, Today, and Tomorrow, edited by David Bowen and Margareta Bowen, 44-52. Amsterdam and Philadelphia: John Benjamins. Doi: 10.1075/ata.iv.10web

\section{Annex 1. Text for the sight translation $\operatorname{task}^{8}$}

(Table 5 to be included here)

\footnotetext{
${ }^{8}$ Participants in the study only had access to the Spanish version. The English translation has been produced for the purpose of the present article.
} 
Annex 2. Participants' profile

(Table 6 to be included here) 